\title{
HEATH PROMOTION AT THE WORKPLACE
}

\author{
By \\ Gamal H. El Samra \\ Professor of Occupational and Environmental Medicine, \\ Faculty of Medicine, Cairo University.
}

\begin{abstract}
:
Health promotion is the process of enabling people to increase control over, and improve, their health through changing lifestyles which contribute to increasing the risk of certain diseases. These are the multifactorial diseases like CVD, DM, peptic ulcer and cancer of various organs. Health promotion programs, therefore, require the active participation of workers in the program. Health promotion programs are active in several areas like : smoking cessation; proper nutrition; fitness and physical activity; dealing with psychosocial stress; alcoholism; addiction and drug abuse; prevention and control of cancer; the health of working women; and the health of older workers .... among others. Smoking, besides the economic loss in production and health care expenditure, is the most important, preventable cause of disease and premature death. It is a risk factor for a number of diseases including COPD and cancer, and affects the reproductive health of working women. Passive smoking also has its serious effects. Health promotion programs advise about healthy nutrition and give recommendations for a balanced diet. Malnutrition and obesity are risk factors for a number of diseases. Physical activity reduces the risk of obesity, hypertension, CVDs, DM, osteoporosis, COPD, low back pain, anxiety and depression. Psychosocial stress is a risk factor for a number of psychosomatic diseases. Industry should launch programs to detect and reduce stress and train workers in coping. Alcoholism, addiction and drug abuse may be the result of various types of stress; industry should attempt to detect, and help authorities to deal with the problem. Morbidity and mortality of cancer can be reduced by : smoking cessation, diet modification, elimination of occupational and environmental carcinogens, screening and appropriate use of up-to-date treatment. Increasing mechanization calls for the application of ergonomics principles to increase productivity and reduce fatigue, accidents and musculoskeletal disorders. Women at work have the same health problems as men, in addition to their special problems which have to be dealt with. These are : breast cancer, cervical cancer, osteoporosis, menstrual disturbances, menopause and family planning. Old age is associated with
\end{abstract}


changes in various body functions. The type of work, work organization and work environment have to be adapted to meet these changes. Government agencies, workers, labour unions and the community should participate in health promotion programs, in collaboration with the occupational health and safety teams at work.

Key words : Health promotion - risk factors - smoking cessation - balanced diet cancer prevention.

\section{Introduction}

The United Nations recognizes that the enjoyment of the highest attainable standard of health is one of the fundamental rights of every human being.

Occupational Health aims at the promotion and maintenance of the highest degree of physical, mental and social well-being of workers in all occupations (WHO,1957) . Appropriate occupational health practice should not be limited to the prevention and control of workrelated hazards, but should deal with the full relationship between work and health and includes health promotion activities. Occupational health requires the active participation of workers in health promotion programs (WHO,1988).

Diseases that can occur among workers are divided into :

- Common diseases

- Common diseases that can be aggravated by work exposures

- Occupational diseases and
- Work-related diseases in which occupational factors may contribute to the causation.

Whereas an occupational disease is caused by a single recognizable factor, a large number of work-related and chronic diseases are caused by a number of risk factors ( multi-factorial diseases ). Risk factors are personal characteristics or lifestyles which characterise a person and place him within a category of persons who are more susceptible to a certain disease or diseases.

Risk factors may be : - Modifiable or Non- modifiable

Non-modifiable risk factors include : age, sex, genetic factors and family history.

Kris- Etherton and Farquhar (1998) gave an example of major modifiable risk factors for coronary heart disease (CHD) which are :

- High total cholesterol and LDL cholesterol

- $\quad$ Blood pressure $>140 / 90$ 
- Low HDL cholesterol

- $\quad$ Smoking

- Diabetes Mellitus

- Obesity and

- Physical inactivity .

The Ottawa Health Promotion Charter (1986) defines " Health Promotion as the process of enabling people to increase control over, and to improve, their health. To reach a state of complete physical, mental and social well-being, an individual or a group of individuals must be able to identify and to realise aspirations, to satisfy needs and to change or cope with the environment...Therefore, health promotion is not just the responsibility of the health sector but goes beyond healthy lifestyles to well- being “.

The Bangkok Charter for the Health Promotion in a Globalized World (WHO,2005) complements and builds upon the values, principles and action strategies of health promotion established by the Ottawa charter, and defines " Health Promotion as the process of enabling people to increase control over their health and its determinants and thereby improve their health ".
Multifactorial diseases are the target for health promotion programs. These programs identify and study the different risk factors that contribute to the causation of diseases, try to modify lifestyles, control work environment and reduce work stress in order to prevent or reduce their occurrence .

Why Health promotion for workers (WHO, 1988; Fielding,1998 and Warshaw and Messite,1998):

Workers are a large, captive group; they spend long hours at work, are easily accessible, easily influenced and in most cases are covered by medical programs to which health promotion programs can be added. Workers follow good models and are influenced by herd psychology.

Management supports health promotion for political and economic reasons, considering that health promotion is the least expensive way of preventing disease .

Some components of a health promotion program :

- Smoking cessation

- Good nutrition

- Fitness and physical activity

- Reduction of psychosocial stress

- Control of alcoholism 
- Control of addiction and abuse of psychoactive drugs

- Cancer prevention and control

- Ergonomics

- Health promotion for working women

- Health promotion for older workers ... ... among others.

When starting an Occupational Health Promotion Program, it does not have to deal with all items mentioned above, to start with. Choice of the components of the program depends on the needs of the population served and the health problems prevailing in the community. The program can be expanded later to include more areas.

\section{Smoking Cessation (WHO,1988; Rudnick, 1998 and Amos and Charlott -Traquet, 1955 ):}

The burden of smoking :

- Smoking is the single, most important, preventable risk factor for disease and premature death. The World Health Organization predicts that by the year 2025 , the number of victims of smoking will reach 8 million every year, most of whom will be in developing countries (Amos and Chaqrlott-Traquet,1955).
- Smoking increases the hazard of certain work exposures ( synergism with asbestos in causing lung cancer ).

- Smoking is responsible for $87 \%$ of the cases of lung cancer, $1 / 3$ of all cancers and for $1 / 6$ of deaths from all causes.

- Smoking increases the risk of CVD, pneumonia, COPD, peptic ulcer and cancer of the bladder.

- In the developing countries, women have been increasingly taking the habit of smoking during the last few decades. The U.S. surgeon general has estimated that among women who smoke, smoking is responsible for about $40 \%$ of heart disease deaths , $55 \%$ of lethal strokes and $80 \%$ of lung cancer deaths.

- Women who smoke have higher rates of cervical cancer. Those who smoke and use contraceptive pills are several times more likely to develop (CVD) than those who use neither (Amos and Charlott-Traquet, 1955). Smoking affects reproductive health, causing menstrual disturbances, increasing the risk of earlier menopause, miscarriage, repeated abortions, ectopic pregnancy

- placental irregularities, vaginal bleeding, preterm birth, low birth 
weight babies and high risk of congenital anomalies ( Rudnik,1998)

. Smoking women are more prone to osteoporosis.

The United States Environmental Protection Agency has ruled that tobacco smoke is considered an occupational hazard to workers, and any ill-health caused by this exposure is compensable ( Rudnick,1998).

\section{Passive smoking :}

Pollution of the in-door environment by tobacco smoke causes :

- Nuisance and eye irritation

- Increases the risk of lung cancer and CVD

- Aggravates asthmatic symptoms .

- Causes reproductive troubles .

- Women's health is affected by passive smoking. Wives of smokers have a high risk of lung cancer (Amos and Charlott-Traquet, 1955).

Loss to industry :

- More hospital admissions and longer stay in hospital.

- Increased medical cost.

- More absenteeism and lower productivity.
- More accidents and more fires.

- Higher medical insurance and accident insurance.

- Higher expenditure for cleaning , ventilation and maintenance of sensitive equipment.

Smoking cessation at work:

Smoking cessation at work needs legislative and administrative action . Certain principles are in use in various workplaces :

$\Rightarrow$ Prohibiting smoking at work altogether.

$\Rightarrow$ Prohibiting smoking in places where flammable or explosive materials are used, as in petroleum refineries and military industries.

$\Rightarrow$ Prohibiting smoking in the presence of carcinogenic exposures that can be aggravated by smoking (e.g. asbestos).

$\Rightarrow$ Prohibiting smoking in-door in closed places.

$\Rightarrow$ In Egypt smoking is regulated by laws 4/1994 (Environmental law ) and $154 / 2007$, which restrict smoking in closed spaces especially in schools, medical units, sporting clubs ....etc. Legislations also put certain restrictions on advertising cigarettes. 
$\Rightarrow$ In the United States of America certain industries implement smoking cessation programs with the objective of finally achieving " Smoke-free Work- Site “ (Rudnick, 1998) .

$\Rightarrow$ The National Institute for Health and Clinical Excellence (UK) (2007) has published the Public Health Intervention Guidance 5, in which recommendations were given on how to encourage and support employees to stop smoking.

$\Rightarrow$ A World Health Organization expert committee on smoking control strategies in developing countries has outlined the basic steps in a smoking control program. These included :

- Information program

- $\quad$ Education program

- Restrictive measures and legislation (WHO,1983).

While every assistance should be provided for those who really need it, most smokers should be able to give up the habit on their own. The major problem for most of them in attempting to do so, lies less in taking the initial decision than in keeping to it and preventing relapse (WHO,1988) .

\section{Nutrition Programs in Industry:}

Malnutrition $\rightarrow$ low calorie intake $\rightarrow$ low productivity and health effects especially where work is hard requiring more calories. A poor diet resulting in undernutrition or malnutrition, reduces working capacity, decreases resistance to disease, increases the rate of absenteeism, causes lack of initiative and drive and increased accident rate (UN FAO, 1963) .

The workplace is suitable for spreading knowledge about proper nutrition. In Egypt, management in many industries provides supplementary meals or snacks to workers on voluntary basis. In remote areas, however, management is required, by law, to feed workers. Health education in proper nutrition, however, is rarely given.

Causes of malnutrition (WHO,1988) :

- Poverty

- $\quad$ Shortage of certain food items

- $\quad$ Bad dietary habits

- Wrong traditional beliefs

- Ignorance .

In developing countries, many societies have been changing their eating habits and becoming more "westernized "; this is not always good. Over-eating and bad dietary habits are risk factors for : 
- CVD

- Hypertension

- $\mathrm{DM}$

- Cancer

- Obesity and over-weight

- Atherosclerosis.

Health promotion programs can provide health education about proper nutrition and healthy dietary habits.

Recommendations for a balanced diet (Kris-Etherton and Farquhar,1998):

- Calories sufficient for the type of job and to maintain a suitable body weight.

- Sugar just enough to provide calories; it serves no other function.

- Fats $<30 \%$ of the calorie requirement ;

$<10 \%$ of calorie requirement of saturated fats

$$
<300 \mathrm{mg} \text { of cholesterol per day. }
$$

- Encourage eating plenty of complex carbohydrates like grains; legumes; leafy vegetables and fruits ; they provide vitamins, minerals and dietary fibers.
- $\quad$ Do not exceed $2400 \mathrm{mg}$ of salt per day.

- $\quad$ Avoid alcohol .

- Use a variety of foods; no single group is sufficient.

- Food supplements include iodine to salt, fluorides to water in certain areas and iron to bread.

- Calcium is needed at all ages :

- $500 \mathrm{mg}$ daily for infants.

- $800 \mathrm{mg}$ daily from infancy to old age.

- $1200 \mathrm{mg}$ daily during adolescence, pregnancy and lactation.

- $1500 \mathrm{mg}$ daily for postmenopausal women and for men after 65 years of age.

- Plenty of water especially in hot environment and when doing hard physical work .

- Antioxidants: vitamins $\mathrm{C}$, and $\mathrm{E}$; beta-carotene and selenium prevent the formation of free radicals and are present in leafy vegetables; red, yellow and orange fruits; citrus fruits; grains and vegetable oils. Selenium is present in grains and fish . 
Planning for occupational nutrition programs should observe traditions and dietary habits of the population served.

Overweight, Obesity and underweight :

Obesity and overweight are caused by :

- High calorie intake

- Physical inactivity

- Genetic causes

- Hormonal causes .

Obesity is a risk factor for hypertension, CVD, hypercholesterolaemia, DM, arthritis, gout and gall bladder disease. Death rate is high if the body mass index ( BMI ) exceeds 25 and is very high if it exceeds 30 ( BMI = body weight in $\mathrm{Kgm} /$ height2 in $\mathrm{m}$ ). Fat distribution is also important; a waist-to-hip ratio close to or above one is associated with a greater risk of hypertension, hyperlipidaemia and DM (Kris-Etherton and Farquhar,1998).

Underweight is a risk factor for gastrointestinal trouble and psychological stress.

Health education in nutrition of female workers is important since the health of children is linked to their own health and nutritional status during pregnancy, and how much they know about infant and child feeding and care. As managers of family food, they play a key role in maintaining a balanced nutritional supply to the family and to the whole community (Viedma,1988).

\section{Fitness and Physical Activity :}

Physically in-active individuals have sickness rates $5-8$ times higher than physically active counterparts (Donoghue,1977).

Physical activity reduces the risk for overweight, hypertension, CHD, DM, osteoporosis, COPD, low back pain, anxiety and depression. It also reduces serum cholesterol and the need for insulin , increases the personal ability to cope with psychosocial stress, and is useful during convalescence from accidents and diseases (WHO,1988).

Each person is the best judge of what kind of exercise suits him or her.

Light exercise, like walking and cycling , is useful for the elderly, obese subjects and those doing sedentary work.

Corry has described in detail a physical training and fitness program and concluded that a well-designed, professionally managed workplace exercise program benefits employees by enhancing their health, well-being, morale and work 
performance. They benefit organizations by improving productivity quantitatively and qualitatively, preventing work-related injuries, accelerating employees' recovery from injury and illness and reducing absenteeism (Corry,1998).

The National Institute for Health and Clinical Excellence (2008) has given formal guidance on how to encourage employees to be physically active.

\section{Reducing psychosocial stress :}

Stress in an inescapable ingredient of the lives of all people every where. Psychosocial stress can be experienced at work and may be caused by high or low work load, lack of control over the job, low decision latitude, job insecurity, boredom, shift work etc..... (Levi,1983). At home, family and financial problems can cause stress. The individual also feels the social, political and financial stresses of the whole community.

Reactions to psychosocial stress are (Levi,1983):

\section{Psychological}

2. Physiological and

3. Behavioural .

Reactions to stress may be short-term and temporary or may be long-term and include (Levi,1983) :
- Psychosomatic diseases like hypertension , DM, CVD and peptic ulcer

- Psychological disorders or

- Behavioural changes like low production, increased accident rates, absenteeism, turnover, addiction, risktaking attitudes, violence, and suicidal tendency.

Through its effect on the immune system, stress has been linked with disease especially viral diseases. Studies have convincingly demonstrated the profound effects that stress can exert in accelerating the development and growth of different malignancies, without actually causing them (Herbert,1994) .

Reducing stress (Warshaw,1998) :

Warshaw has described a stress management program which consisted of :

Managing stress- related symptoms : case finding and dealing with individuals suffering from symptoms:

Awareness that many recurrent or persistent somatic complaints may be attributable to stress.

Recognition that when a number of employees in a particular unit or area in the workplace present such functional complaints, search should be initiated for a 
cause that could be a controllable stressor.

Reaching out to individuals involved in or witnessing a fatal accident or an episode of violence.

Reducing individual vulnerability : Help, educate and train individual workers to cope with stress more effectively.

Interpersonal relations at work : considering the diversity of the workforce , the discriminatory behaviour of managers and supervisors and acts of harassment or violence among workers, these should be promptly corrected and disciplinary action taken.

Managing job- related stress : Work load, decision latitude, boredom, shift work, job insecurity, delayed or premature promotion ...etc.

Managing organization's stress : The organization as an entity is subject to stressors which could be reflected on the employees. Examples of organization stress is economic crises, changing top management, plant closing or relocation and downsizing. All efforts made by management to correct the situation and remove the stress should be communicated to the employees.

Help to manage personal stress : arising at home or in the community , which, although this is individual concern, it does affect the worker's performance at work. Management will find it beneficial to provide assistance to the workers in dealing with stresses of that sort.

Moral support from family, fellow workers, supervisors, management and the whole community will help.

Stress is highly contagious, so dealing with stress is both therapeutic and preventive.

\section{Alcoholism :}

Alcoholism is an important risk factor for work accidents and disability, and causes higher absenteeism rates and low productivity.

Alcoholics report sickness $3-11$ times more than non-alcoholics, and suffer more from liver disease, nervous troubles, gastrointestinal disorders, cardiac dysfunction or malnutrition.

Social, cultural or psychosocial stress may be the underlying cause for alcoholism. Industry, helped by the whole community, should attempt to solve the problems, help alcoholics to quit and rehabilitate them . It is not advisable to fire the alcoholic but rather help him to get back on the job . 
The extent of the problem of alcoholism varies in different communities; in Egypt it is not one of the serious problems.

\section{Control of addiction and abuse of psychoactive drugs :}

Addiction and abuse of psychoactive drugs are major risk factors for work accidents, higher absenteeism rates, lower productivity and destruction of work equipment (WHO,1988).

Addicts report absenteeism 2 - 3 times more than normal, are involved in accidents 4 times more and have 25 times as many days absence (WHO,1988).

Women and men respond differently to alcohol and drugs; women having a lower tolerance to most substances. Since many women addicts are in the child-bearing age, the effects on the developing foetus are a serious concern (Bergendahl and LeeNah,1995).

Community programs are required to help detect, treat and rehabilitate addicts and prevent relapse .

\section{Cancer prevention and control :}

The morbidity and mortality of cancer can be markedly reduced if the following

$$
\text { recommendations are followed }
$$
(Greenwald and Warshaw,1998):
1. - Smoking cessation

2. - Dietary modification

3. - Elimination of occupational and environmental carcinogens

4. - Screening and

5. - Appropriate use of up-to-date treatment .

Risk Factors for Cancer (Greenwald and Warshaw,1998):

$\Rightarrow$ In smokers (smoking 25 cigarettes/day) , cancer risk is 20 times higher than in non-smokers; smoking cessation reduces the risk, but it remains high for many years.

$\Rightarrow$ Genetic factors : the use of this principle in prevention is not yet practical .

$\Rightarrow$ Humoral factors : as in cancer of the prostate.

$\Rightarrow$ Hormones : some hormones are risk factors for cancer ( sex hormones ) and others are used for treatment. The use of hormones in treatment is better avoided except perhaps in Hormone Replacement Therapy (HRT) in menopause where they should be used under strict medical supervision.

$\Rightarrow$ Diet : of all cancer deaths, $35 \%$ could be related to dietary habits. These are 
due to lung cancer, colorectal, breast, prostate, stomach, ovarian and urinary bladder cancers.

Of the foods that can be blamed are :

- Fats :

-Total fats and saturated fats : increase the risk for cancers of the colon and prostate and for breast cancer after menopause .

-Polyunsaturated vegetable oils : increase the risk for cancers of the prostate and the breast after menopause.

-Highly polyunsaturated, Omega-3 fatty acids : reduce the risk for cancers of the colon and breast.

- Dietary fibers and certain constituents of vegetables, fruits and grains reduce the risk for cancers of the breast and colon.

- $\quad$ Micronutrients :

-Antioxidants : vitamins $\mathrm{C}, \mathrm{E}$ and beta carotene reduce the risk for cancer.

-The incidence of lung cancer is lower in subjects consuming quantities of fruits and vegetables.

-Lower zinc and selenium intake increases the risk of cancer.
- Alcohol :

-Alcohol increases the risk for cancers of the colon, pancreas, breast and liver.

-There is a synergistic relation between alcohol and smoking in causing cancers of the mouth, pharynx, oesophagus and larynx.

Dietary recommendations for the prevention of cancer (Greenwald and Warshaw,1998) :

Less than $30 \%$ of the caloric intake of fats .

Dietary fibers : $20-30 \mathrm{gm}$, not more than $35 \mathrm{gm} /$ day.

Plenty of fruits and vegetables .

Avoid Obesity .

No alcohol.

Avoid salted or smoked foods ( they increase the risk for cancers of the stomach and oesophagus).

$\Rightarrow$ Infection :

1. Hepatitis B and C increase the risk for hepatic cell carcinoma; a vaccine against hepatitis B is now available.

2. HIV is a risk factor for Kaposi sarcoma. 
3. Urinary Bilharziasis is a risk factor for cancer of the bladder .

4. Chronic prostatitis is a risk factor for cancer of the prostate .

5. Human papilloma virus causes cervical cancer.

6. Epstein-Barr virus causes Burkitt's lymphoma.

\section{Prevention and control of cancer :}

depends upon :

1. Smoking cessation

2. Dietary modification

3. Control of exposure to carcinogens

4. Control of infections that are risk factors for cancer

5. Screening for early detection of the disease

6. Health education .

Screening for cancer:

Cancer of the breast : Breast selfexamination (BSE) and Mammography.

The American Cancer Institute recommends screening for symptomless women, 40 - 49 years of age, once every 1 -2 years; and for those who have high risk factors, screening should start earlier. It has also been reported that screening for cancer of the breast every 1- 2 years of women 50 -69 years of age reduces cancer mortality by up to $30 \%$ (Last,1998).

- Cervical cancer : Cytology for cervical smear (Pap smear)

- Colo-rectal cancer : Clinical examination per rectum (digital and sigmoidoscopic) Blood in stools

- Prostate : Estimation of Prostate Specific Antigen ( PSA )

- Lung : Sputum examination for malignant cells has not proved to be of value in reducing lung cancer mortality .

\section{8 . Ergonomics ( WHO,1988):}

Ergonomics deals with the relationship between the worker, machine and the environment and aims at reducing fatigue during work, reducing accident frequency, increasing productivity and maintaining the optimum state of health of the worker, especially in relation to musculoskeletal disorders . It is concerned with adopting the appropriate position at work, proper design of the machine and work space and adapting the machine to the physical and mental characteristics of the worker. Ergonomics 
principles apply work psychology in relation to man and machine and in design of controls and displays. Control of physical and chemical hazards at the workplace is also an important ergonomics principle.

Musculoskeletal syndromes as tension neck and low-back pain are important causes of absenteeism.

Design of work space and machinery should take in consideration the body measurements and physical and mental capabilities of women, minors, the elderly and the handicapped.

Health promotion programs can be useful in educating workers and explaining ergonomics principles, changing work practices to reduce accidents and fatigue and modifying human behaviour to reduce musculoskeletal disorders.

\section{Health Promotion for working women (Last.1998):}

Women have a longer life expectancy than men ; the extra years have their health problems. Besides suffering almost all diseases that men suffer, they have their own health problems which men do not share. An additional problem is their double employment at work and at home. Their reproductive role also imposes particular stresses and risks on women.
Working women, especially those of low socio-economic standard, do not have a clear understanding of many health problems and how to deal with them. Health promotion programs provide health education, counselling and preventive services. In the work atmosphere, women, as a group, are more receptive to advice regarding the change of behaviour and participation in health promotion programs.

\section{Special problems :}

- $\quad$ Breast cancer

- Cervical cancer

- Osteoporosis : is a problem of women after menopause ( 6 times more in women than in men between $50-70$ years ).

To reduce the incidence of osteoporosis:

In spite of the fact that some risk factors for osteoporosis are non-modifiable like age, sex and genetic factors, others are modifiable and provide the basis for prevention, like :

1. Diet : give calcium + vitamin $D$

2. Physical activity: walking for 45 60 minutes three times per week

3. No smoking/ drinking/ or drugs

4. (HRT) (under medical supervision)

5. Health education . 


\section{Menstrual Disturbances :}

In most women, menstruation causes no problem, while in others a little pain and discomfort will keep the worker from going to work at regular times of the month, which could be embarrassing. In other cases, medical attention is needed.

\section{Premenstrual Syndrome :}

This is a group of physical and mental symptoms occurring for 1 week to 10 days before menstruation, affecting some women and may affect the ability to do work.

It needs either : - No intervention,

- Reassurance and changing lifestyle regarding diet, beverages and physical activity or

- Medical treatment.

- Menopause :

Menopausal symptoms : need :

- Health education

- Counselling

- $\quad$ Keep working

- HRT reduces osteoporosis and coronary heart disease.

\section{Family Planning .}

\section{Health Promotion for Older Workers} (Crawford et al.,2009) :

There is a need to maintain the health of the over 50's at work. There is a number of physical, physiological, psychological and psychosocial changes with ageing that can be moderated by physical activity, intellectual activity, modification of work practices and other lifestyle changes.

Physical changes :

1. Reduced aerobic capacity

2. Increased time for recovery

3. Reduction of stature

4. Increased body mass index

5. Decreased muscle strength

6. Increased incidence of musculoskeletal disorders (MSDs)

7. Balance is affected.

Psychological, physiological and psychosocial changes :

8. Decreased thermal tolerance.

9. Increased reaction time and improved skills and experience.

10. The need for intellectual stimulation. 
Work Organization :

11. Excessive overtime in physically demanding jobs has an adverse effect.

12. Work ability is reduced in shift work especially in women.

Sensory abilities :

13. Vision and hearing are affected. Accidents :

14. Risk of accidents is less, but injuries are more severe and take longer to recover.

Ill-health :

15. The most frequent work-related diseases are MSDs, stress reactions, depression and anxiety.

Older workers need (Crawford et al.,2009) :

- Physical exercise .

- To ensure that the physical demand of the job does not outstrip the physical ability.

- Give longer time for recovery between tasks.

- Improve the environment to cope with the decreased heat tolerance and the visual and auditory changes.
- Increased reaction time is only a problem in a high risk environment.

- The ability to learn must be considered , together with the need to maintain and update their skills.

- Shift work should be designed using ergonomics principles.

- Intellectual stimulation.

- Balanced diet.

- Social support, risk reduction strategies for stress and to improve coping.

\section{Different parties concerned with health promotion :}

The European Agency for Safety and Health at Work (2010) has recommended that workplace health promotion is to be a joint effort of employers, employees and the society .

The following agencies and groups participate in the provision of health promotion programs :

$\Rightarrow$ Ministries and Government Agencies .

$\Rightarrow$ Businessmen and industrial management

$\Rightarrow$ Labour unions

$\Rightarrow$ Workers 
$\Rightarrow$ Community participation

- $\quad$ Primary health care workers

- $\quad$ NGOs

- Universities, private practitioners and religious leaders

- $\quad$ Community leaders

- Schools

$\Rightarrow$ Occupational Health and Safety Team at work .

\section{Abbreviations}

- $\quad$ BMI : Body Mass Index

- BSE : Breast Self-examination

- CHD : Coronary Heart Disease

- COPD : Chronic Obstructive Pulmonary Disease

- CVD : Cardiovascular Disease

- $\quad$ DM : Diabetes Mellitus

- HRT : Hormone Replacement Therapy

- MSDs : Musculoskeletal Disorders.

\section{References}

1. Amos, A. and Charlott-Traquet, C. (1955). Women and tobacco. World Health 48. September, Special Issue: 22-3.

2. Bergendahl, P. and Lee-Nah, H. (1995). Women and substance abuse. World Health 48 JulySeptember: 12-3.
3. Corry, J. (1998). Health protection and promotion. Physical training and fitness programmes : an organizational asset. In : Stellman, J. M., ed. Encyclopaedia of Occupational Health and Safety, vol. 1, 4th edition. International Labour Office, Geneva. Pp. 15.28-31.

4. Crawford, J.O., Graveling, R. A., Cowie, H., Dixon , K. and MacCalman, L. (2009). The health, safety and health promotion needs of older workers. Report submitted to the IOSH committee. Institute of Occupational Medicine. Edinburgh, U.K.

5. Donoghue,S. (1977). The correlation between physical fitness, absenteeism and work performance. Canad. J. Publ. Hlth 68:201-3.

6. European Agency for Safety and Health at Work (2010): Workplace health promotion. http://osha.europa.eu/en/topics/whp/index_html

7. Fielding, J.E. (1998).Health protection and promotion. Worksite health promotion. In : Stellman, J.M., ed. Encyclopaedia of Occupational Health and Safety, vol. 1, 4th edition. International Labour Office, Geneva. Pp. 15.8-11.

8. Greenwald, P. and Warshaw, L. J. (1998). Health protection and promotion. Cancer prevention and control. In: Stellman, J. M., ed. Encyclopaedia of Occupational Health and Safety, vol. 1, 4th edition. International Labour Office, Geneva. Pp. 15.43-7.

9. Herbert, T. B. (1994). Stress and the immune system. World Health 47: 4-5.

10. Kris-Etherton, P.M. and Farquhar, J.W. (1998). Health protection and promotion. Worksite nutrition programmes. In : Stellman, J.M., ed. Encyclopaedia of Occupational Health and Safety, vol. 1 , 4th edition. International Labour Office, Geneva. Pp.15.32-6.

11. Last, P. A. (1998). Health protection and promotion. Women's Health. In: Stellman, J. M., ed. Encyclopaedia of Occupational Health and Safety, vol. 1, 4th edition. International Labour Office, Geneva. Pp. 15.48-52. 
12. Levi L. (1983) . Stress. In : Parmeggiani, L., ed. : Encyclopaedia of Occupational Health and Safety, vol. 2, 3rd edition. International Labour Office, Geneva. Pp. 2106-11.

13. National Institute of Health and Clinical Excellence. U.K. (2007). Workplace health promotion : How to help employees to stop smoking. Public Health Intervention guidance 5.

14. National Institute of Health and Clinical Excellence, U.K. (2008). Workplace health promotion : How to encourage employees to be active .

15. Ottawa Charter for Health Promotion (1986). Health Promotion 1:iii-v.

16. Rudnick, J. (1998). Health protection and promotion. Smoking control in the workplace. In : Stellman, J. M., ed. Encyclopaedia of Occupational Health and Safety, vol. 1, 4th edition. International Labour Office, Geneva. Pp. 15.37-40.

17. United Nations Food and Agriculture Organization (1963). Freedom From Huger Campaign. Nutrition and Working Efficiency . Rome, Italy.

18. Viedma, C. (1988). Health and Nutrition Atlas. World Health 40: 25.
19. Warshaw, J. (1998). Health protection and promotion. Stress management programmes. In : Stellman, J. M. ed. Encyclopaedia of Occupational Health and Safety, vol. 1, 4th edition. International Labour Office, Geneva. Pp. 15.70-1.

20. Warshaw , L.J. and Messite , J. (1998). Health protection and promotion. Health protection and promotion in the work place. In : Stellman, J.M., ed. Encyclopaedia of Occupational Health and Safety, vol. 1, 4th edition. International Labour Office . Geneva. Pp. 15.2-7.

21. World Health Organization, Technical Report Series No. 135. (1957) . Joint ILO/WHO committee on Occupational Health. 3rd report. WHO. Geneva.

22. World Health Organization, Technical Report Series No. 695. (1983) . Smoking Control Strategies in Developing Countries. WHO. Geneva.

23. World Health Organization, Technical Report Series No. 765. (1988). Health promotion for working populations. WHO, Geneva

24. World Health Organization's Bangkok Charter for Health Promotion in a Globalized World (2005). WHO, Geneva. 